\title{
Managing microvesicles or Virchow's vicissitude
}

\author{
Hunter Moore, $\mathrm{MD}, \mathrm{PhD},{ }^{\mathrm{a}}$ and Alden Harken, $\mathrm{MD}^{\mathrm{b}}$
}

The referenced article, ${ }^{1}$ originally published in the Journal of the American College of Cardiology and carefully reviewed by Fremes and Tam, ${ }^{2}$ presents some surprises for cardiovascular surgeons who hold these truths to be selfevident: (1) The most robust determinate of vascular graft patency is distal runoff; (2) arterial grafts are superior to venous grafts because arterial vascular endothelium is tougher than venous; and (3) hypercoagulability does occur infrequently, but it is a poor excuse for a thrombosed graft. It is not Rudolf Virchow's fault. He was interested in pulmonary embolism, and the "Virchow's triad" concept was not coined until a century after Dr Virchow's death.

The working hypothesis of the index study is that the preoperative signature of a patient's circulating microvesicles (MVs) promotes a procoagulant profile of proteins that predict post-coronary artery bypass grafting (CABG) occlusion at 18 months.

The study reports an analysis of plasma samples collected from 330 consecutive patients undergoing elective CABG from a single institution. At 18 months, computed tomography angiography of 179 patients identified 43 patients with at least 1 occluded graft; of these, 30 patients' plasma samples were available for MV analysis (cases). A nested case-control analysis comparing the MV signature of 30 age- and sex-matched patients with patent grafts (control) with the group with occluded grafts (cases) was performed. Demographic, hematologic, European System for Cardiac Operative Risk Evaluation, comorbidity, and arterial graft use were similar between groups.

MVs are believed to be a form of circulating communication between cells, which is an extension of intracellular signaling through small lipid bilayer molecules. ${ }^{3}$ There are diverse types of vesicles that differ in function and originate from different cell lines as mentioned by Camera and colleagues. ${ }^{1}$ Beyond extracellular communication, these extracellular vesicles can directly modify the environment in which they circulate by providing a tissue factor-rich phospholipid surface serving as an important point of contact for

From the ${ }^{\mathrm{a}}$ Department of Surgery, University of Colorado, Denver, Colo; and ${ }^{\mathrm{b}}$ Department of Surgery, University of California, San Francisco-East Bay, Oakland, Calif. Received for publication Aug 18, 2020; revisions received Sept 10, 2020; accepted for publication Sept 16, 2020; available ahead of print Nov 10, 2020.

Address for reprints: Alden Harken, MD, Department of Surgery, University of California, San Francisco-East Bay, Oakland, CA 94602 (E-mail: alden.harken68@ gmail.com).

J Thorac Cardiovasc Surg 2022;163:696-7

0022-5223/ $\$ 36.00$

Copyright $₫ 2020$ Published by Elsevier Inc. on behalf of The American Association for Thoracic Surgery

https://doi.org/10.1016/j.jtcvs.2020.09.144

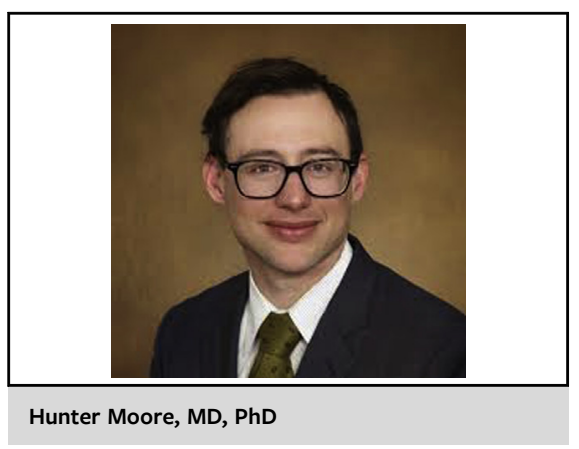

CENTRAL MESSAGE

Can we manage MVs or will they manage us?

See Commentaries on pages 698,700 , and 701

coagulation initiation. ${ }^{4}$ Platelet microparticles have received the most attention because of their impact on coagulation, their association with thrombotic complications, and their cross-talk with inflammation. ${ }^{5}$ The complexity of these extracellular signaling molecules extends beyond the measurement of cell surface markers because the contents and size of MV are dependent on the activation status of the platelet. $^{6}$ This can also be extrapolated to other MVs derived from endothelium and inflammatory cell lines, making cell surface markers a technique for quantification, but an important consideration is that not all vesicles with the same surface expression are the same.

Despite these limitations, the authors compiled a preoperative MV score composed of $6 \mathrm{MV}$ subtypes. Functional MV analysis indicated that MVs from patients with occluded grafts could generate more thrombin at higher rates than MVs from controls. Before surgery, MVs were more plentiful and platelet-derived MVs were in 2-fold higher concentration in patients who would later have occluded grafts. The authors then developed an MV scoring system that would have successfully predicted $100 \%$ graft patency in patients with an MV score less than 2. In patients with an MV score of 6, however, all patients had at least 1 occluded graft at 18 months. Comparing MV scores above and below 3 , the area under the receiver operating curve was 0.9. Clinically, major cardiovascular events were more frequent in the high MV signature group.

MVs with tissue factor expression may help explain systemic hypercoagulability beyond Virchow's triad. The cellbased model of hemostasis as proposed by Hoffman and Monroe $^{4}$ has implicated the importance of tissue factor- 
bearing cells as the initiator of clot formation, in addition to the platelet phospholipid surface. Elevated CD41 and CD14 MV at 18 months, as demonstrated by Camera and colleagues, ${ }^{1}$ support that inflammatory and plateletderived microparticles are associated with graft thrombosis, rather than endothelial-derived MV. This is further supported by the proteomic work implicating platelets and inflammation upregulation in the graft occlusion cohort. The role of inflammation driving coronary artery disease is well established, ${ }^{7}$ and the associated microparticles provide another potential mechanism for an acute on chronic pathogenesis for vessel thrombosis. The authors demonstrated that high MV concentrations directly lead to increased thrombin generation. Although these MV numbers were elevated in the patients with thrombosis at the time of CABG, the gap was widened at 18 months. Vascular graft occlusion, like most other pathological processes such as cancer and the response to stress/trauma, has been linked to the magnitude of the induced inflammation. For example, the higher the burden (disseminated vs local) of cancer, the higher the rate of thrombotic events. ${ }^{8}$

The timing of MV to thrombosis of the graft and the associated increased thrombin generation pose therapeutic potential and practical hurdles. Any measure of direct inhibition or chelation of the pathogenic MV is not in clinical practice and would be cost prohibitive. The other option, as proposed by the authors, is to augment platelet inhibition with a dual antiplatelet therapy. The third option, in the high-risk population, would be reduction in thrombin generation using a conventional anticoagulant such as Coumadin, Xa, or direct thrombin inhibitor. Previous studies on goal-directed therapies based on coagulation measurements have demonstrated improvement in survival $^{9}$ and blood product use ${ }^{10}$ in hypercoagulable patient groups. Therefore, targeting hypercoagulability to improve vessel patency is a natural progression in personalized medicine. Perhaps cardiac surgeons have been too critical of their technical skills, as hypercoagulability in transplant surgery is becoming increasingly accepted as contributory to arterial thrombosis. ${ }^{11}$

A real surprise is that the venous and arterial grafts were occluded late at a similar frequency $(13.3 \%$ venous vs $16.9 \%$ arterial), and the authors adhered to the standard "no touch" graft harvesting strategies.

Vascular runoff remains important, perhaps the arterial and venous endovasculature is more similar than we had thought, and the really good news is that blaming a patient's hypercoagulability may now be a valid excuse and no longer a cop-out.

The authors are to be congratulated for accomplishing a clinically relevant study with immediate predictive risk and even possible eventual targetable therapies. We conclude that these investigators have identified a relationship that warrants corroboration and the attention of the readers of the Journal.

\section{Conflict of Interest Statement}

The authors reported no conflicts of interest.

The Journal policy requires editors and reviewers to disclose conflicts of interest and to decline handling or reviewing manuscripts for which they may have a conflict of interest. The editors and reviewers of this article have no conflicts of interest.

\section{References}

1. Camera M, Brambilla M, Canzano P, Cavallotti L, Parolari A, Tedesco CC, et al. Association of microvesicles with graft patency in patients undergoing CABG surgery. J Am Coll Cardiol. 2020;75:2819-32.

2. Fremes SE, Tam DY. Microvesicles and coronary artery bypass graft patency: double trouble or a chance for personalized surgery? J Am Coll Cardiol. 2020; 75:2833-5.

3. Veziroglu EM, Mias GI. Characterizing extracellular vesicles and their diverse RNA contents. Front Genet. 2020;11:700.

4. Hoffman M, Monroe DM III. A cell-based model of hemostasis. Thromb Haemost. 2001;85:958-65.

5. Melki I, Tessandier N, Zufferey A, Boilard E. Platelet microvesicles in health and disease. Platelets. 2017:28:214-21.

6. Ponomareva AA, Nevzorova TA, Mordakhanova ER, Andrianova IA, Rauova L, Litvinov RI, et al. Intracellular origin and ultrastructure of platelet-derived microparticles. Thromb Haemost. 2017;15:1655-67.

7. Hansson GK. Inflammation, atherosclerosis, and coronary artery disease. N Engl J Med. 2005;352:1685-95.

8. Gade IL, Braekkan SK, Naess IA, Hansen JB, Cannegieter SC, Overvad K, et al. The impact of initial cancer stage on the incidence of venous thromboembolism: the scandinavian thrombosis and cancer (STAC) cohort. Thromb Haemost. 2017; $15: 1567-75$.

9. Gonzalez E, Moore EE, Moore HB, Chapman MP, Chin TL, Ghasabyan A, et al. Goal-directed hemostatic resuscitation of trauma-induced coagulopathy: a prag matic randomized clinical trial comparing a viscoelastic assay to conventional coagulation assays. Ann Surg. 2016;263:1051-9.

10. Dias JD, Sauaia A, Achneck HE, Hartmann J, Moore EE Thromboelastography-guided therapy improves patient blood management and certain clinical outcomes in elective cardiac and liver surgery and emergency resuscitation: a systematic review and analysis. Thromb Haemost. 2019;17: 984-94.

11. Pomposelli JJ. Hepatic artery thrombosis after liver transplant: not a surgical problem? Transplantation. 2016;100:2251.

Key Words: CABG thrombosis, microvesicles 